\title{
Bone health comparison in seven Asian countries using calcaneal ultrasound
}

\author{
Marlena C Kruger ${ }^{1 *}$, Joanne M Todd ${ }^{2}$, Linda M Schollum²,3, Barbara Kuhn-Sherlock ${ }^{2,3}$, Drew W McLean ${ }^{2}$ \\ and Kim Wylie ${ }^{1}$
}

\begin{abstract}
Background: Bone density measurements by DXA are not feasible for large population studies, whereas portable ultrasound heel scanners can provide a practical way of assessing bone health status. The purpose of this study was to assess bone health in seven Asian countries using heel ultrasound.
\end{abstract}

Methods: Stiffness index (SI) was measured and T-scores generated against an Asian database were recorded for 598,757 women and 173,326 men aged over 21 years old using Lunar Achilles (GE Healthcare) heel scanners. The scanners were made available in public centres in Singapore, Vietnam, Malaysia, Taiwan, Thailand, Indonesia and the Philippines.

Results: The mean SI was higher for men than women. In women SI as well as T-scores declined slowly until approximately 45 years of age, then declined rapidly to reach a mean T-score of $<-2.5$ at about $71-75$ years of age. For men, SI as well as the T-score showed a slow steady decline to reach a mean of -2.0 to -2.5 at about $81-85$ years. The results for females indicate that there are differences in the rate of decline between countries (significant differences between the slopes at $P<0.05$ ). Vietnam had the fastest decrease for both T-Score and SI, resulting in this population having the poorest bone health of all countries at older ages. The results for males aged $46-85$ years indicate that there are no significant differences in the rate of decline between countries for SI and T-Score. In both men and women aged 46-85 years, Vietnam and Indonesia have the lowest SI as well as T-Score for all age groups. For Vietnam and Indonesia, more than $50 \%$ of the women could be at risk of having osteoporosis and related fractures after the age of 70 , while in Thailand and the Philippines this was $>80$ years.

Conclusions: The heel scan data shows a high degree of poor bone health in both men and women in Asian countries, raising concern about the possible increase in fractures with ageing and the expected burden on the public health system.

Keywords: Heel ultrasound, Asia, Risk for osteoporosis

\section{Background}

According to the International Osteoporosis Foundation's Asian Audit, published in 2009, the incidence of hip fracture has risen 2- to 3-fold in most Asian countries over the past 30 years [1-4]. Hip fracture rates in Hong Kong and Singapore are approaching those observed in US Caucasians [5]. The increased prevalence of osteoporosisassociated peripheral and vertebral fractures will also lead to an increase in socioeconomic burdens due to related costs for the public health system in the Asian region $[2,5,6]$.

\footnotetext{
* Correspondence: m.c.kruger@massey.ac.nz

${ }^{1}$ Institute of Food, Nutrition and Human Health, Massey University, Private Bag 11222, Palmerston North 4442, Palmerston North, New Zealand Full list of author information is available at the end of the article
}

Bone mineral density using DXA is the standard diagnostic technique for osteoporosis but the cost is relatively high, and there is a shortage of DXA machines through most of the developing Asian countries [4]. Most of these machines are also located in the urban areas and therefore not accessible by the rural population. DXA is not ideal for community based studies, as DXA machines cannot be transported to rural areas and the cost of a scan is significant $[7,8]$.

The general recommendation in Europe for DXA machines is 0.11 per 10,000 population (www.iofbonehealth. org) [4]. Most of the Asian countries are well below this ratio, with the ratio for Indonesia at 0.001 per 10,000 population for example, more than 70-fold lower [4]. As a
C Biomed Central

(c) 2013 Kruger et al.; licensee BioMed Central Ltd. This is an Open Access article distributed under the terms of the Creative Commons Attribution License (http://creativecommons.org/licenses/by/2.0), which permits unrestricted use, distribution, and reproduction in any medium, provided the original work is properly cited. 
result of this lack of available DXA technology, other clinical prediction tools have been developed, such as the Osteoporosis Self-assessment tool (OSTA) [9] and the Kohn Kaen Osteoporosis Study Score (KKOS) $[10,11]$ in order to attempt to identify people at risk of osteoporosis and therefore who should receive a DXA scan. The FRAX $^{\circledR}$ tool has been developed by the World Health Organisation (WHO) to evaluate fracture risk of patients [12]. It is based on individual patient models that integrate the risks associated with clinical risk factors as well as bone mineral density (BMD) at the femoral neck. But the FRAX $^{\circledR}$ has not been validated for Asian populations with the exception of China, Hong Kong, the Philippines, Sri Lanka, Singapore and Taiwan [13].

Quantitative ultrasound (QUS) may offer an alternative tool for screening or assessment of risk of poor bone health in large populations. QUS measures the peripheral skeleton, and may give some assessment of bone microarchitecture in addition to bone mass [14]. It is relatively inexpensive, and is portable, and therefore could be used as a tool to screen for poor bone health at the community level [8]. QUS has also been shown to be as good as bone mineral density (BMD) assessed by DXA in predicting fracture risk [15]. Previous studies have shown that broad band attenuation (BUA) of QUS correlates moderately well with bone density by DXA [16]. The Lunar Achilles from GE Healthcare has been US FDA-approved for three clinical uses: It can predict the risk of hip fracture comparable to DXA at hip/spine; 2) it has valid T-scores for use in the same way as DXA at hip/spine, and 3) it has precision for monitoring bone changes in older populations (PMA number P970040).

There are very little data on the prevalence of low bone mass in several Asian countries. There have been population studies done in Taiwan including over 16,000 volunteers [14], Vietnam [8,17], and The Asian Osteoporosis Study (AOS) $[1,5,18]$. Lin et al. [14], reported mild to severe osteoporosis in $54 \%$ of the volunteers aged 50 and older living in Taiwan, while Hien et al. [8] and Thuy et al. [17] reported the prevalence of osteoporosis as 39\% of women over the age of 50 years living in Hanoi City.

To date, there has not been a comprehensive assessment of bone health across the Asian region. The aim of the present study was to assess calcaneal stiffness index and T-scores using QUS in seven Asian countries from a large self-selected population. We hypothesised that the pattern of bone loss will be different between countries as well as between males and females.

\section{Methods}

In this descriptive study, the Lunar Achilles Insight or Express (GE Healthcare, Madison, WI, USA) heel scanners were made available in several public centres such as shopping centres, community gatherings and office buildings in Singapore, Vietnam, Malaysia, Taiwan, Thailand, Indonesia and the Philippines between 2006 and 2009. Men and women attending the locations were invited to have their heel scanned. Only age and gender were recorded and there were no inclusion/ exclusion criteria in place, although all individuals signed a registration form. The individuals who volunteered to be scanned would have had to be ambulatory as they were visiting a public place. The information was gathered during public events and each individual consented to their information being stored.

Stiffness index (SI) was generated using broadband ultrasound attenuation and speed of sound measurements for 598,757 women and 173,326 men aged $\geq 20$ years old. T-scores were then generated against the Asian reference population database provided with the heel scanners. The Achilles systems are non-invasive dry systems, which take 2-3 minutes to scan. For all subjects, the scan measured the right calcaneus.

Calibration was performed on each scan day according to manufacturer's instructions. The Achilles systems use high frequency sound waves to evaluate bone status in the heel. They measure speed of sound (SOS) and broadband ultrasound attenuation (BUA) and combine them to form a clinical measure called the Stiffness Index. The manufacturers cited precision error for the SI measurement is $2.4 \%$. As multiple scanners were used in various countries at the same time, they were not cross calibrated.

The SI was used to calculate a T-score based on a healthy young adult reference population. There have been 6 clinical studies involving 10,000+ women from which the reference population was created, and the ability to express and interpret results as T-scores were derived. This can be used to determine an individual's risk of poor bone health. Therefore a T-score of $>-1$ was classified as normal, a score of $<-0.1$ and $>-2.5$ was classified as being at risk of having osteopenia while a T-score of $<-2.5$ was classified as at risk of having osteoporosis as per the FDA approval. The latter approach was reinforced by the position statement from the International Society for Clinical Densitometry (ISCD) [19]. While the QUS should not be used to diagnose osteoporosis, thresholds were defined as above to identify patients at high or low risk of having osteoporosis and being at risk of fracture.

Multiple studies using the Lunar Achilles QUS systems [19-22] have confirmed that the system has a $90 \%$ sensitivity for detecting osteoporosis at the spine and hip, using an Achilles T-Score referral threshold of -0.8 to -1.2 . Using an Achilles T-score of -2.5 has been shown to provide a specificity of more than $90 \%$ for identifying only those subjects at high risk. Individuals with an Achilles T- 
score above -1.0 are considered at low risk for having osteoporosis, while those with an intermediate score of -1.0 to -2.5 may have some risk of low bone mass, and those with a $\mathrm{T}$-score of $<-2.5$ are considered at high risk of having osteoporosis and a high fracture risk. These cutoffs were used to interpret the data obtained from the Achilles units used in this project.

\section{Data analysis}

SI and T-scores were averaged for each 5 years age group and each country and are presented as mean and standard deviation for each age group and country as well as separately for males and females. Two-way Analysis of Variance (ANOVA) was used on the means to test for the effects of age and gender and their interaction on T-score and SI. Analysis of Covariance (ANCOVA) was used to compare the rates of decline in T-score and SI over age during the period of linear decline (age 46-85 years). Piecewise polynomial regression was used to test whether the rates of decline are similar in the 21 to 45 and $46-85$ year age groups.

\section{Results}

Figure 1 summarises the age and gender distribution of the participants. In total we report data from 598,757 heel scans for women, and 173,326 scans for men over the age of 20 years. The number of subjects per country and gender are presented in Table 1.

Tables 2 and 3 and Figures $2 \mathrm{~A}$ and $\mathrm{B}$ compare the rate of bone loss with age between men and women. The statistical analyses indicate that there is an interaction between age group and gender, indicating that the differences between men and women vary between age groups (Tables 2 and 3). The rate of loss is faster in the younger men compared to women aged between 21 and
55. Bone loss in the men is slow yet steady over time, while the rate of loss remains slow in the women, up until the age of 50 after which it increases rapidly. Women at age 55-60 reach a mean T-score of -1.0 which could indicate that many of these women may have low bone mass and could be at risk of having osteopenia [22]. The men already reach a mean T-score of -1.0 at age $46-50$ which may indicate low bone mass at a much younger age compared to women.

\section{Data for women aged 21-90+ years old}

Figure 3 shows the rate of decline in SI from the women scanned aged 46 to 85 . The women from Indonesia in general have the lowest SI of all countries. The results for the women indicate that there is a significant difference in the rate of decline of SI between countries $(\mathrm{P}<0.05)$ with Vietnam having a faster decline than the Philippines (0.84 units decline per additional year of age for Vietnam versus 0.6 units decrease per additional year of age for the Philippines). There is no difference in the rate of decline of the measured SI between the other countries. In the 46-50 year old age group, women from Indonesia have a significantly lower SI than Malaysia, Singapore, Taiwan and Thailand. In the same age group women from Taiwan have the highest SI, significantly higher than the mean SI for Indonesia, Philippines and Vietnam. In the 76 to 80 year age group, Vietnam and Indonesia have a significantly lower SI in comparison to all the other countries $(\mathrm{P}<0.05)$; in the same age group, women from Taiwan has the highest SI but it is only significantly higher than those from Vietnam and Indonesia. There are no significant differences in the SI's measured for this age group between Malaysia, Philippines, Singapore, Taiwan and Thailand.

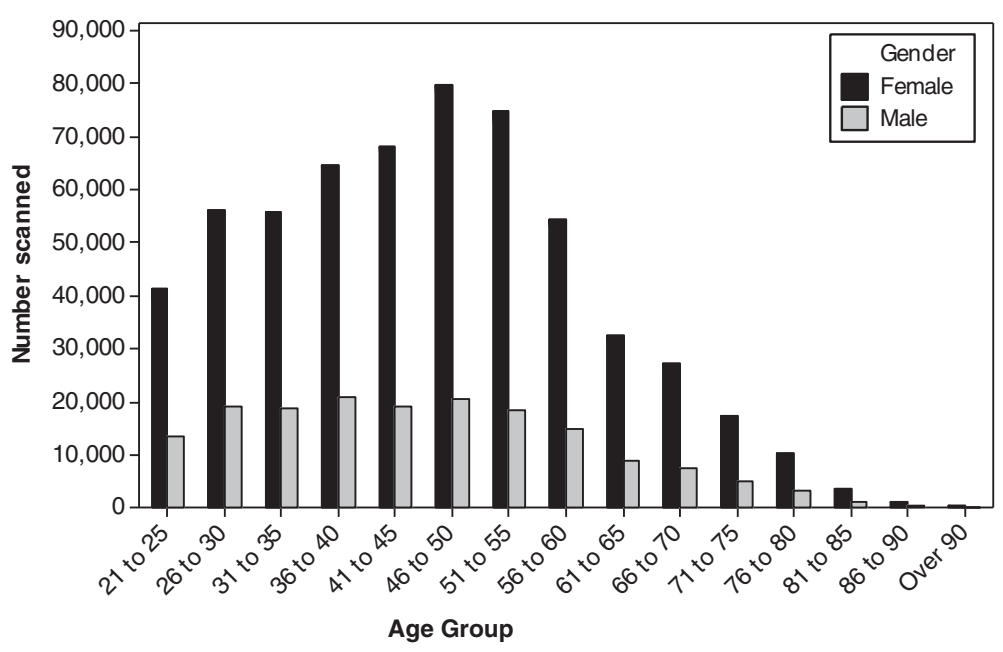

Figure 1 Number of males and females scanned per age group. 
Table 1 Number of subjects per country and gender

\begin{tabular}{lccc}
\hline Country & Female & Male & All \\
\hline Indonesia & 85864 & 36594 & 122458 \\
\hline Malaysia & 120085 & 59458 & 179543 \\
\hline Philippines & 105467 & 25527 & 130994 \\
\hline Singapore & 16174 & 6563 & 22737 \\
\hline Taiwan & 18309 & 6714 & 25023 \\
\hline Thailand & 13280 & 3150 & 16430 \\
\hline Vietnam & 239578 & 35320 & 274898 \\
\hline All & $\mathbf{5 9 8 7 5 7}$ & $\mathbf{1 7 3 3 2 6}$ & 772083 \\
\hline
\end{tabular}

The relevant T-scores are summarized in Table 4. The mean T-score for the young women at 20 years was low at between 0 and 0.5 , and showed only a slight decline to approximately the age of 45 , and then a rapid decline reaching a mean $\mathrm{T}$-score of $\leq-2.5$ at about $71-75$ years of age. Women from Indonesia aged over 46 years, had significantly lower T-scores compared to all the other countries, but the rate of decline was faster in women aged 46-85 years from Vietnam. Women from Taiwan had the highest T-scores, significantly higher than Vietnam, Indonesia, Malaysia and Philippines but not Singapore and Thailand $(\mathrm{P}<0.05)$.

\section{Data for men aged 20-90+ years old}

Figure 4 shows the rate of decline in the SI in men aged between 46 and 85 years old. The rate of decline is the fastest in Indonesia and the Philippines: 0.60 and 0.67 units decrease per additional year of age versus 0.29 to 0.45 units decrease per additional year of age for the remaining countries. The difference in decline between Philippines, Taiwan and Thailand is marginally significant, but there is no difference in the decrease observed between any of the other countries. In the 46 to 50 year age group, Vietnam has the lowest SI and the Philippines the highest; this difference is significant $(\mathrm{P}<0.05)$. All other countries are similar and none of the other differences are significant. In the 76 to 80 year age group, Indonesia has the lowest SI. In the same age group, Malaysia, Singapore, Taiwan, and Thailand have the highest SI, significantly higher than Indonesia. The Philippines and Vietnam have SIs below these countries but the difference is not statistically different.

The T-scores for men slowly decline from age 26-30 reaching a mean of $\leq-2.5$ for some countries at about

Table 2 ANOVA for the effects of age and gender on stiffness index

\begin{tabular}{lccccc}
\hline Source & DF & Type III SS & Mean Square & F Value & Pr $>$ F \\
\hline Sex & 1 & 4687.067 & 4687.067 & 186.7 & $<.0001$ \\
\hline Age & 14 & 22248.93 & 1589.209 & 63.3 & $<.0001$ \\
\hline Sex Age & 14 & 1286.161 & 91.86863 & 3.66 & $<.0001$ \\
\hline
\end{tabular}

Table 3 ANOVA for the effects of age and gender on T-Score

\begin{tabular}{lccccc}
\hline Source & DF & Type III SS & Mean Square & F Value & Pr $>$ F \\
\hline Sex & 1 & 0.001243 & 0.001243 & 0.01 & 0.9375 \\
\hline Age & 14 & 178.8685 & 12.77632 & 63.37 & $<.0001$ \\
\hline Sex*Age & 14 & 21.42922 & 1.530658 & 7.59 & $<.0001$ \\
\hline
\end{tabular}

81-85 years (Table 5). There are no significant differences between the rates of decline of the T-score between countries. The men from Indonesia and Vietnam had the lowest T-scores and greatest risk of poor bone health compared to the other countries but the rate of decline in the T-score (0.032 units decrease per additional year) between age 46 and 85 years was similar in all countries.

\section{Discussion}

Several studies have now shown that QUS at peripheral sites can be used as a screening tool to assess bone health $[8,14,17,20,21]$. Speed-of-sound measurements at the calcaneus can identify persons at risk of osteoporotic fracture as reliably as bone mineral density measurements [22,23] and could be an ideal tool to screen for osteoporosis at the community level [24-26]. In the current study we aimed to assess bone health in several Asian countries using the GE Achilles Insight or Express machine, and then to comment on the prevalence of low bone mass in men and women aged between 20 and $90+$ years in these countries. The SI and T-scores were generated by the units, and the ISCD criteria [19] were used to classify people at risk of poor bone health. Our data show a high degree of poor bone health in both men and women in the seven Asian countries where we conducted the assessments.

The younger males in general had a higher SI compared to females aged between 21-40 while the T-scores for both men and women aged between 20 and 25 were between 0 and 0.5 . Bone loss was slow in the women up to the age of 45-50, after which it increased significantly, with more than $50 \%$ of the women being at risk of being osteoporotic at age 70+ years. In men, bone loss was at a similar rate from age 20 to 90 years with more than $50 \%$ being classified as being at risk of being osteopenic or osteoporotic at age $80+$ years. Similar differences in rates of bone loss were also reported by Lin et al. [14] in a Taiwanese population which also had an increased rate of bone loss in women compared to men, after the age of 60 years.

The prevalence of low bone mass was highest in Indonesia for both women and men. In the 46-50 age groups, Indonesia had a significantly lower SI than Malaysia, Singapore, Taiwan and Thailand. In Indonesia up to $70 \%$ of women and men over 50 years could be 

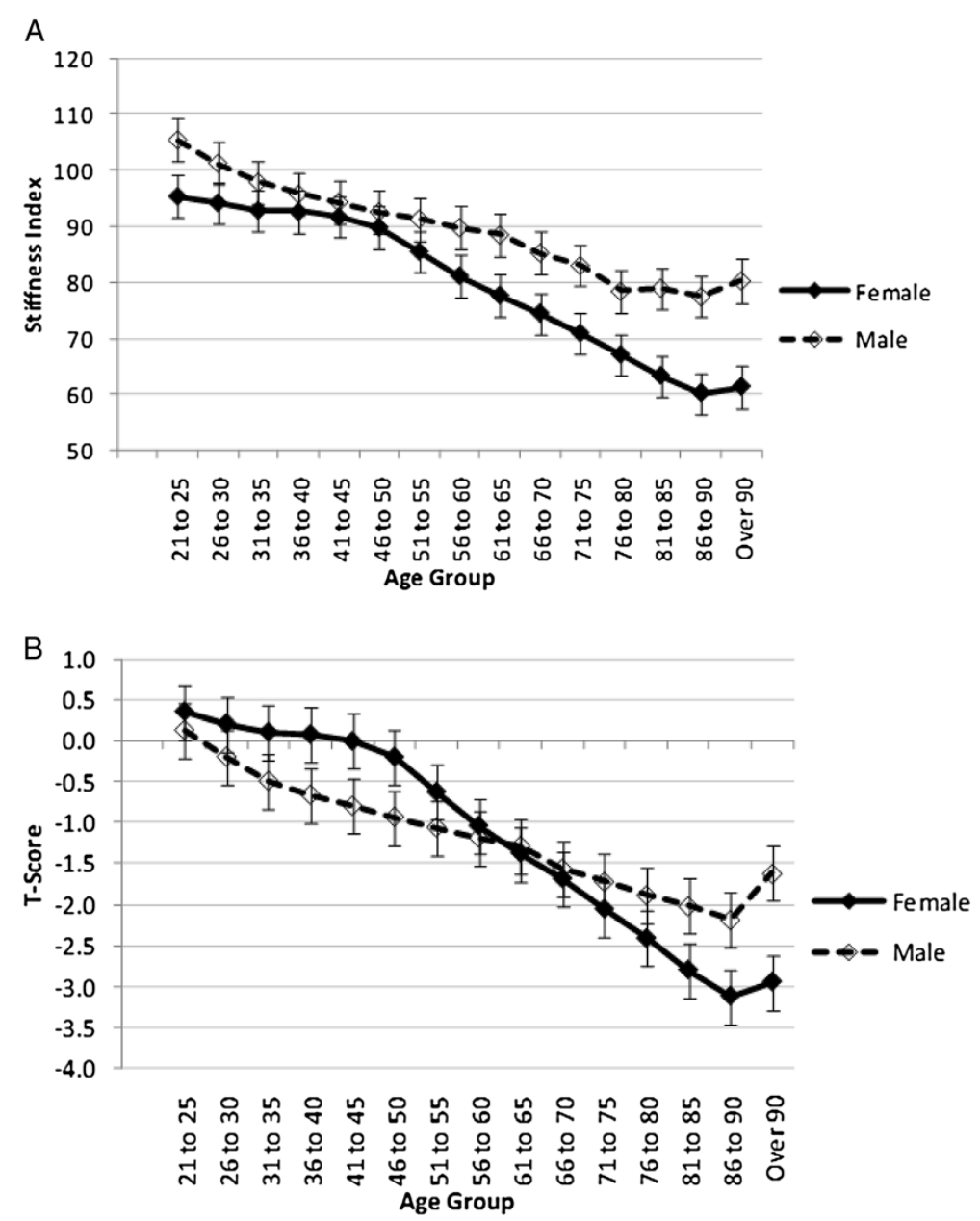

Figure 2 A and B: Comparison of SI and T-scores between males and females. Data is presented as LS mean and 95\% confidence intervals.

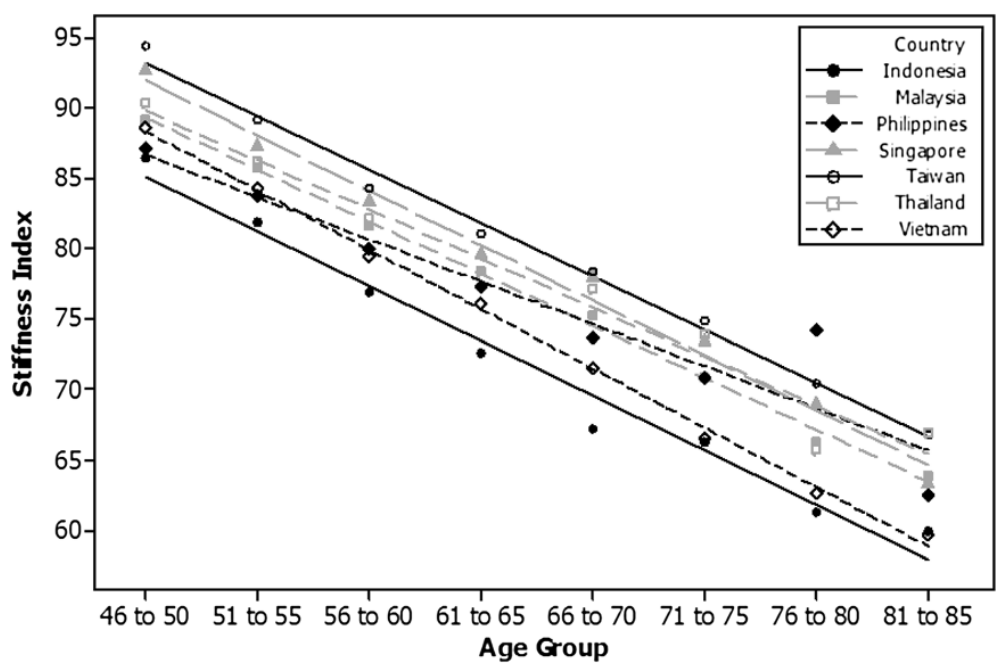

Figure 3 Rate of decrease in SI of women aged between 46 and 85 years. 
Table 4 T-Score by country and age group - females (mean and standard deviation)

\begin{tabular}{lllllllllllllll}
\hline Age Group & \multicolumn{2}{c}{ Indonesia } & \multicolumn{2}{c}{ Malaysia } & \multicolumn{2}{c}{ Philippines } & \multicolumn{2}{c}{ Singapore } & \multicolumn{2}{c}{ Taiwan } & \multicolumn{2}{c}{ Thailand } \\
\hline 21 to 25 & -0.21 & 1.487 & 0.28 & 1.818 & -0.17 & 1.703 & 0.86 & 2.085 & 0.76 & 2.089 & 0.46 & 1.812 & 0.45 & 2.102 \\
\hline 26 to 30 & -0.34 & 1.438 & 0.14 & 1.801 & -0.38 & 1.720 & 0.66 & 1.960 & 0.77 & 2.008 & 0.33 & 1.760 & 0.24 & 1.965 \\
\hline 31 to 35 & -0.36 & 1.444 & 0.02 & 1.791 & -0.20 & 1.751 & 0.30 & 1.910 & 0.61 & 1.804 & 0.19 & 1.699 & 0.14 & 1.982 \\
\hline 36 to 40 & -0.35 & 1.485 & -0.07 & 1.726 & -0.19 & 1.652 & 0.39 & 1.896 & 0.50 & 1.918 & 0.21 & 1.758 & 0.03 & 1.922 \\
\hline 41 to 45 & -0.43 & 1.488 & -0.13 & 1.696 & -0.22 & 1.699 & 0.26 & 1.884 & 0.56 & 1.890 & -0.00 & 1.721 & -0.12 & 1.927 \\
\hline 46 to 50 & -0.61 & 1.524 & -0.28 & 1.675 & -0.47 & 1.573 & 0.09 & 1.821 & 0.27 & 1.833 & -0.12 & 1.651 & -0.29 & 1.884 \\
\hline 51 to 55 & -1.05 & 1.475 & -0.60 & 1.618 & -0.79 & 1.649 & -0.44 & 1.676 & -0.26 & 1.709 & -0.54 & 1.573 & -0.73 & 1.785 \\
\hline 56 to 60 & -1.53 & 1.420 & -1.01 & 1.568 & -1.06 & 1.419 & -0.83 & 1.599 & -0.73 & 1.568 & -0.95 & 1.567 & -1.20 & 1.644 \\
\hline 61 to 65 & -1.92 & 1.468 & -1.32 & 1.533 & -1.27 & 1.685 & -1.20 & 1.435 & -1.06 & 1.508 & -1.32 & 1.459 & -1.55 & 1.627 \\
\hline 66 to 70 & -2.38 & 1.466 & -1.62 & 1.571 & -1.70 & 1.697 & -1.37 & 1.631 & -1.32 & 1.552 & -1.45 & 1.549 & -1.99 & 1.628 \\
\hline 71 to 75 & -2.52 & 1.473 & -2.07 & 1.513 & -2.06 & 1.490 & -1.82 & 1.605 & -1.68 & 1.593 & -1.77 & 1.681 & -2.51 & 1.518 \\
\hline 76 to 80 & -2.92 & 1.490 & -2.50 & 1.516 & -1.63 & 2.040 & -2.27 & 1.787 & -2.11 & 1.622 & -2.59 & 1.403 & -2.87 & 1.494 \\
\hline 81 to 85 & -3.04 & 1.522 & -2.75 & 1.641 & -2.89 & 1.380 & -2.82 & 1.572 & -2.43 & 1.576 & -2.48 & 1.949 & -3.18 & 1.495 \\
\hline 86 to 90 & -3.00 & 1.780 & -2.83 & 1.564 & -3.45 & 1.517 & -3.57 & 1.421 & -2.14 & 2.063 & -3.26 & 1.266 & -3.57 & 1.526 \\
\hline Over 90 & -2.22 & 2.027 & -1.93 & 2.754 & -2.92 & 2.160 & -2.70 & $*$ & -3.30 & 1.505 & -3.90 & $*$ & -3.63 & 1.965 \\
\hline
\end{tabular}

"indicates insufficient data.

classified as at risk of being either osteopenic or osteoporotic. Data from the Indonesian Osteoporosis society (PEROSI) suggest that about $41.8 \%$ of men and $90 \%$ of women are osteopenic, while $28.8 \%$ of men and $32.3 \%$ of women have osteoporosis as per the WHO criteria $[4,19]$. These data do not define the age groups and can therefore not be directly compared to our study. Our published data on a small cohort of postmenopausal women in Indonesia revealed that $66.3 \%$ could be classified as being either osteopenic or osteoporotic, according to DXA of the lumbar spine [27].

In Taiwan the percentage of women over 50 years with low bone mass was $47.5 \%$ while the percentage for men was $57.1 \%$. Chie et al. [28] reported that the incidence of hip fracture in Taiwanese women over 50 years was similar to those recorded for Western countries, but that the age-specific incidence of hip fracture of elderly Taiwanese men was higher than in US Caucasian men, at about 65\% that for women. The QUS data for the Philippines indicate a prevalence of low bone mass in $59.3 \%$ in women over 50 years and $56.6 \%$ in older men. In a previous study using DEXA, we found $67.2 \%$ of postmenopausal women had low bone mass in the lumbar spine [27]. However, this was a small study including only 58 women, and so may not be representative of the total population. Miura et al. [29] reported a $19.8 \%$ prevalence of osteoporosis in urban postmenopausal women in the Philippines, using QUS. Our data using QUS indicate the percentage at risk of

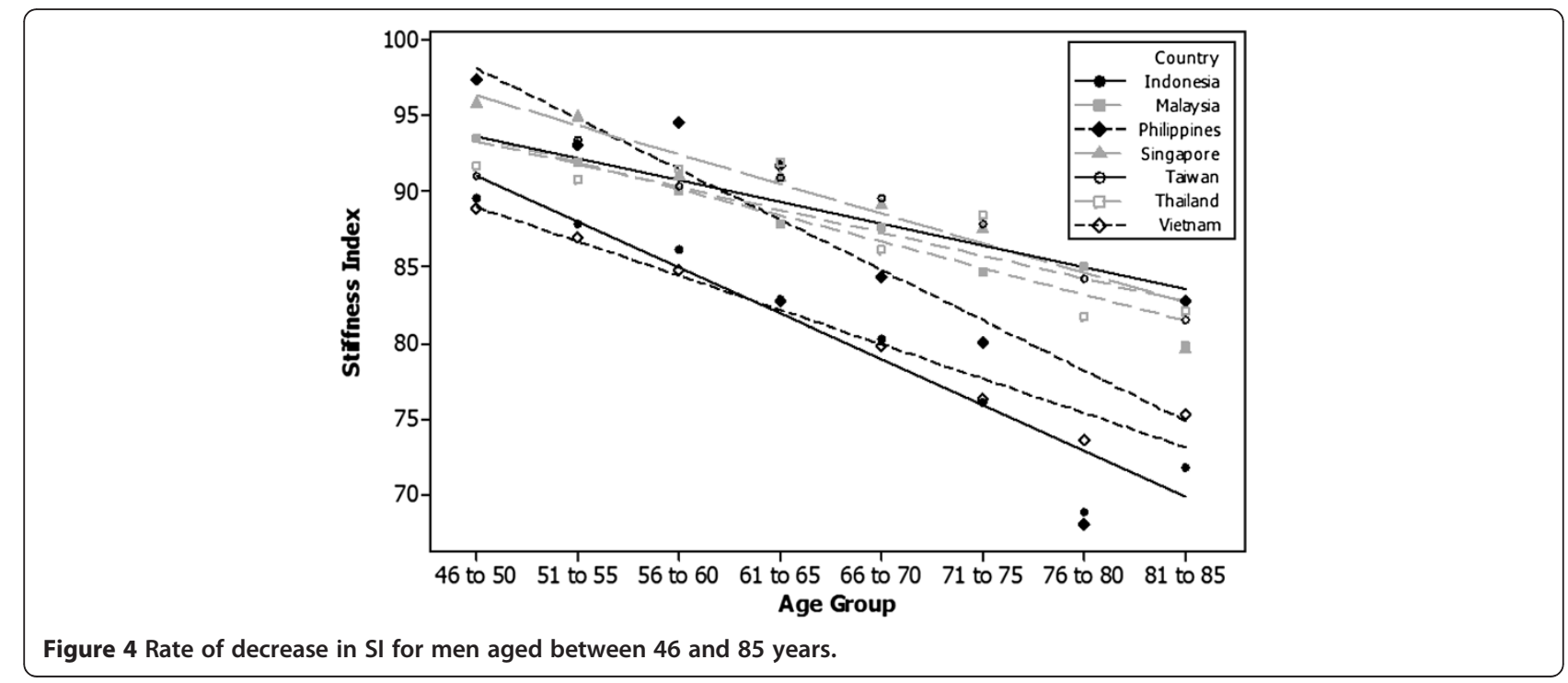


Table 5 T-Score by country and age group - males (mean and standard deviation)

\begin{tabular}{lllllllllllllll}
\hline Age Group & \multicolumn{2}{c}{ Indonesia } & \multicolumn{2}{c}{ Malaysia } & \multicolumn{2}{c}{ Philippines } & \multicolumn{2}{c}{ Singapore } & \multicolumn{2}{c}{ Taiwan } & \multicolumn{2}{c}{ Thailand } \\
\hline 21 to 25 & -0.14 & 1.387 & 0.18 & 1.703 & -0.22 & 1.602 & 0.34 & 1.565 & 0.21 & 1.932 & 0.42 & 1.790 & 0.04 & 1.725 \\
\hline 26 to 30 & -0.46 & 1.391 & -0.20 & 1.622 & -0.42 & 1.451 & -0.04 & 1.643 & 0.06 & 1.692 & -0.03 & 1.728 & -0.34 & 1.827 \\
\hline 31 to 35 & -0.66 & 1.349 & -0.50 & 1.533 & -0.75 & 1.719 & -0.44 & 1.519 & -0.06 & 1.883 & -0.38 & 1.652 & -0.68 & 1.639 \\
\hline 36 to 40 & -0.75 & 1.338 & -0.64 & 1.502 & -0.71 & 1.587 & -0.54 & 1.518 & -0.65 & 1.611 & -0.40 & 1.671 & -0.96 & 1.599 \\
\hline 41 to 45 & -0.79 & 1.367 & -0.75 & 1.476 & -0.76 & 1.532 & -0.54 & 1.532 & -0.82 & 1.517 & -0.75 & 1.735 & -1.16 & 1.506 \\
\hline 46 to 50 & -1.05 & 1.308 & -0.86 & 1.465 & -0.54 & 1.445 & -0.71 & 1.532 & -1.08 & 1.792 & -1.04 & 1.467 & -1.24 & 1.490 \\
\hline 51 to 55 & -1.24 & 1.324 & -1.00 & 1.415 & -0.97 & 1.628 & -0.79 & 1.445 & -0.89 & 1.490 & -1.12 & 1.387 & -1.40 & 1.512 \\
\hline 56 to 60 & -1.42 & 1.333 & -1.15 & 1.442 & -0.83 & 1.339 & -1.10 & 1.427 & -1.14 & 1.451 & -1.06 & 1.477 & -1.58 & 1.489 \\
\hline 61 to 65 & -1.69 & 1.373 & -1.32 & 1.417 & -1.01 & 1.422 & -1.11 & 1.405 & -1.11 & 1.490 & -1.02 & 1.444 & -1.73 & 1.499 \\
\hline 66 to 70 & -1.96 & 1.398 & -1.35 & 1.455 & -1.64 & 1.872 & -1.26 & 1.484 & -1.22 & 1.387 & -1.51 & 1.468 & -1.99 & 1.497 \\
\hline 71 to 75 & -2.23 & 1.353 & -1.59 & 1.488 & -1.93 & 1.259 & -1.40 & 1.381 & -1.34 & 1.610 & -1.32 & 1.392 & -2.22 & 1.492 \\
\hline 76 to 80 & -2.53 & 1.374 & -1.56 & 1.497 & -1.65 & 1.954 & -1.41 & 1.686 & -1.67 & 1.367 & -1.87 & 1.553 & -2.49 & 1.562 \\
\hline 81 to 85 & -2.32 & 1.435 & -1.99 & 1.664 & -1.77 & 1.337 & -2.06 & 1.194 & -1.87 & 1.360 & -1.84 & 1.520 & -2.28 & 1.736 \\
\hline 86 to 90 & -2.78 & 1.211 & -1.41 & 1.738 & -3.16 & 1.019 & -1.92 & 1.955 & -0.67 & 1.971 & -2.27 & 1.872 & -3.08 & 1.416 \\
\hline Over 90 & -2.48 & 1.642 & -1.22 & 1.977 & -1.53 & 2.003 & 0.17 & 0.666 & -3.02 & 2.220 & $*$ & $*$ & -3.27 & 1.182 \\
\hline
\end{tabular}

indicates insufficient data.

osteoporosis to be $22.1 \%$, similar to the data reported by Miura et al. [30].

Our data from Thailand could have underestimated the prevalence of low bone mass, as differences in the age ranges in various publications make direct comparisons difficult. Pongchaiyakul et al. [31], reported the prevalence of osteoporosis by femoral neck or lumbar spine BMD using DXA, to be $33 \%$ in women older than 60 years, while we report that up to $17 \%$ of women over 60 years could be at risk of having osteoporosis and another study showed the prevalence of osteoporosis to be $50 \%$ in women over 70 years old [32]. As mixed results have been reported for Thai women, Pongchaiyakul et al. [33] examined the prognostic value of combining QUS with clinical risk factors, using a cohort of women aged between 38 and 85 years, and found the prevalence of osteoporosis to be $12.7 \%$ in this group of women. Age, weight and QUS outcomes were significantly associated with osteoporosis risk. The latter study suggests that a combination of QUS with age and weight could be used to create a normogram to be used to estimate the risk for poor bone health in Asian women.

The reported data raise a concern for bone health in the wider Asian region. Hip fracture rates in Hong Kong and Singapore have been reported to be approaching those recorded for Caucasians [5], and while the rates are lower for countries such as Malaysia and Thailand, they are likely to increase. In China, at this time, more than 69 million people over the age of 50 suffer from osteoporosis, with 687,000 hip fractures each year. WHO estimated that more than $50 \%$ of hip fractures will occur in Asia by 2050 [6], and the number of people with hip fracture in Asia will be about 3.2 million per year [2,6]. A recent review by Cooper et al. [34] suggested that while hip fracture rates may be reaching a plateau in the Western world, there is an increasing ageadjusted incidence rate of hip fractures among Asian men and women. The cost associated with hip fractures is substantial; the combined annual cost of all osteoporotic fractures has been estimated to be $\$ 20$ billion in the USA, and 30 million Euros in the European Union [34].

QUS can predict the risk of wrist and osteoporosisrelated fractures [35], the risk of vertebral fractures $[23,25,36]$, the risk of hip fractures $[15,37,38]$ and can discriminate between women with and without vertebral fractures [23,38] and hip fractures [22,35,37]. Heel QUS is also strongly correlated with the strength of the proximal femur [39]. Our data could therefore indicate that the risk of osteoporotic fracture is high in women and men over the age of 70 years living in the seven countries where we collected data.

Risk factors for low bone mass in Asia include low calcium in the diet, and relatively high occurrence of vitamin D insufficiency. Mean daily calcium intakes in the seven countries vary between just above $200 \mathrm{mg}$ in Indonesia and Thailand [27,40] to about $450 \mathrm{mg}$ for Malaysia, Singapore and Taiwan [18,41]. Suboptimal vitamin $\mathrm{D}$ status has also been widely reported for many Asian countries. We reported mean $25(\mathrm{OH})$ vitamin $\mathrm{D}_{3}$ levels for postmenopausal women in Jakarta, Indonesia to be $45.06 \mathrm{nmol} / \mathrm{L}$ (range 41.02 - 49.09) and for women living in Manila, Philippines to be $62 \mathrm{nmol} / \mathrm{L}$ (range 56.2 - 67.7) [27]. Other reported values are $52 \mathrm{nmol} / \mathrm{L}$ for Thailand [4], and $44 \mathrm{nmol} / \mathrm{L}$ for postmenopausal women living in Malaysia [42]. In all of the above mentioned studies, a significant negative correlation was reported between serum 
$25(\mathrm{OH})$ vitamin $\mathrm{D}_{3}$ and Parathyroid hormone (PTH) levels $[40,42,43]$. There is also a strong relationship between suboptimal vitamin D status, high PTH levels and the risk for hip fractures [43-46].

The present study had limitations: firstly, none of the QUS bone density measurements were validated against a DXA measurement for the same person; secondly, the QUS data can only identify people at risk of low bone mass, and is not a diagnostic tool. Thirdly, participants were self-selected and primarily from urban areas. And lastly, measuring bone density using QUS does not capture the Z-score which may have been more informative for the younger populations; the SI as well as generated $\mathrm{T}$-scores were used as proxy measurements.

\section{Conclusions}

The results presented here provide a snapshot of the bone health status of participants from seven regions in South East Asia. Overall results indicate that there is extensive poor bone health in both males and females living these regions. The measured SI's indicate low bone mass even among young men and women, and the patterns of bone loss were very similar. We conclude that the data presented may indicate that the risk of having low bone mass and osteoporotic fractures is high in women and men over the age of 70 years living in these countries with the highest risk being for people living in Indonesia and Vietnam.

There is a strong need to continue to develop detailed, robust evidence of bone health status in communities throughout South East Asia. Osteoporosis has a severe effect on the quality of life and independence of sufferers, and is a considerable socio-economic burden for individuals, communities and the public health systems $[4,5]$. Studies such as these will contribute to an accurate assessment of bone health and its prevalence which will help to provide valuable information for the development and implementation of tailored health promotion campaigns, improved patient care, and reduced economic burdens.

\section{Competing interests}

MC Kruger, K Wylie - none.

JM Todd, LM Schollum, B Kuhn-Sherlock, DW McLean - employed by Fonterra Co-operative Group Ltd.

\section{Authors' contributions}

MK was the primary author; JT and LMS edited the manuscript, BKS was responsible for the statistical analyses and graphics; DWM and KW were responsible for data capture and entry. All authors read and approved the final manuscript.

\section{Acknowledgement}

This study was funded by Fonterra Brands (Singapore) Ltd.

\section{Author details}

${ }^{1}$ Institute of Food, Nutrition and Human Health, Massey University, Private Bag 11222, Palmerston North 4442, Palmerston North, New Zealand.
${ }^{2}$ Fonterra Co-operative Ltd, Private Bag 92032, Auckland, New Zealand. ${ }^{3}$ Fonterra Research and Development Centre, Private Bag 11029, Palmerston North 4442, New Zealand.

Received: 12 June 2012 Accepted: 27 December 2012

Published: 5 March 2013

\section{References}

1. Lau EMC, Lee JK, Suriwongpaisal P, Saw SM, Das De S, Khir A, Sambrook P: The incidence of hip fracture in four Asian countries: the Asian osteoporosis study (AOS). Osteoporos Int 2001, 12(3):239-243.

2. Suzuki T: Risk factors for osteoporosis in Asia. J Bone Min Metab 2001, 19:133-141.

3. Jordan KM, Cooper C: Epidemiology of osteoporosis. Best Practice Res Clin Rheumatol 2002, 16(5):795-806.

4. Mithal A, Dhingra V, Lau E: The Asian Audit: Epidemiology, costs and burden of osteoporosis in Asia. International Osteoporosis Foundation 2009. www.iofbonehealth.org.

5. Lau EMC: Osteoporosis - a worldwide problem and the implications in Asia. Annals Acad Med 2002, 31(1):67-68.

6. Cooper C, Melton LJ: Epidemiology of osteoporosis. Trends Endocrinol Metab 1992, 3:224-229.

7. Fogelman I, Blake GM: Different approaches to bone densitometry. J NuCl Med 2000, 41:2015-2025.

8. Hien VTT, Khan NC, Lam NT, Mai LB, Le DNT, Nhung BT, Nakamori M, Kunii $D$, Sakai T, Yamamoto S: Determining the prevalence of osteoporosis and related factors using quantitative ultrasound in Vietnamese adult women. Am J Epidemiol 2005, 161(9):824-830.

9. Skedros JG, Sybrowsky CL, Stoddard GJ: The osteoporosis self-assessment screening tool: a useful tool for the orthopaedic surgeon. J Bone Joint Surg 2007, 89:765-772.

10. Pongchaiyakul C, Nguyen ND, Pongchaiyakul C, Nguyen TV: Development and validation of a new clinical risk index for prediction of osteoporosis in Thai women. J Med Assoc Thai 2004, 87(8):910-916.

11. Pongchaiyakul C, Wanothayaroj E: Performance of the Khon Kaen Osteoporosis Study (KKOS) score for identifying osteoporosis in men. J. Med Ass. Thai 2007, 90(8):1518-1523.

12. Kanis JA, Oden A, Johansson H, Borgström F, Ström O, McCloskey E: FRAX ${ }^{\circledR}$ and its applications to clinical practice. Bone 2009, 44:734-743.

13. Tsang SWY, Kung AWC, Kanis JA, Johansson H, Oden A: Ten-year fracture probability in Hong Kong southern Chinese according to age and BMD femoral neck T-scores. Osteoporos Int 2009, 20:1939-1945.

14. Lin J-D, Chen J-F, Chang H-Y, Ho C: Evaluation of bone mineral density by quantitative ultrasound of bone in 16862 subjects during routine health examination. Brit J Radiol 2001, 74:602-606.

15. Damilakis J, Maris TG, Karantanas AH: An update on the assessment of osteoporosis using radiologic techniques. Eur Radiol 2007, 17(6):1591-1602

16. Trimpou P, Bosaeus I, Bengtsson B-A, Landin-Wilhelmsen K: High correlation between quantitative ultrasound and DXA during 7 years of follow-up. Eur J Radiol 2010, 73:360-364.

17. Thuy VTT, Chau TT, Cong ND, De DV, Nguyen TV: Assessment of low bone mass in Vietnamese: comparison of QUS calcaneal ultrasonometer and data-derived T-scores. J Bone Min Metabol 2003, 21:114-119.

18. Lau EMC, Suriwongpaisal P, Lee JK, Das De S, Festin MR, Saw SM, Khir A, Torralba T, Sham A, Sambrook P: Risk factors for hip fracture in Asian men and women: the Asian osteoporosis study. J Bone Min Res 2001, 16(3):572-580.

19. Krieg M-A, Barkmann R, Gonnelli S, Stewart A, Bauer DC, Barquero LDR, Kaufman JJ, Lorenc R, Miller PD, Olszynski WP, Poiana C, Schott A-M, Lewiecki EM, Hans D: Quantitative ultrasound in the management of osteoporosis: the 2007 ISCD official positions. J Clin Densitom: Assess of Skelet Health 2008, 11:163-187.

20. Miller PD, Njeh CF, Jankowski LG, Lenchik L: What are the standards by which bone mass measurement at peripheral skeletal sites should be used in the diagnosis of osteoporosis. J Clin Densitometry 2002, 5:S39-S45.

21. Burke PK, Burke G: Use of heel ultrasound to screen for osteoporosis: comparison with spine and femur DXA. J Bone Min Res 2003, 18:S207.

22. Frost ML, Blake GM, Fogelman I: Contact quantitative ultrasound: An evaluation of precision, fracture discrimination, age-related bone loss and applicability of the WHO criteria. Osteoporos Int 1999, 10:441-449. 
23. Glüer CC, Eastell R, Reid DM, Felsenberg D, Roux C, Barkmann R, Timm W, Blenk T, Armbrecht G, Stewart A, Clowes J, Thomasius FE, Kolta S: Association of five quantitative ultrasound devices and bone densitometry with osteoporotic vertebral fractures in a population-based sample: the OPUS study. J Bone Min Res 2004, 19(5):782-793.

24. Hans D, Dargent-Molina P, Schott AM, Sebert JL, Cormier C, Kotzki PO, Delmas PD, Pouilles JM, Breart G, Meunier PJ: Ultrasonographic heel measurements to predict hip fractures in elderly women: the EPIDOS prospective study. Lancet 1996, 348(9026):511-514.

25. Pluijm SMF, Graafmans WC, Bouter LM, Lips P: Ultrasound measurements for the prediction of osteoporotic fractures in elderly people. Osteoporos Int 1999, 9:550-556.

26. Krieg MA, Cornuz J, Ruffieux C, Sandini L, Büche D, Dambacher MA, Hartl F, Häuselmann HJ, Kraenzlin M, Lippuner K, Neff M, Pancaldi P, Rizzoli R, Tanzi F, Theiler R, Tyndall A, Wimpfheimer K, Burckhardt P: Comparison of three bone ultrasounds for the discrimination of subjects with and without osteoporotic fractures among 7562 elderly women. J Bone Min Res 2003, 18(7):1261-1266.

27. Kruger MC, Schollum LM, Kuhn-Sherlock B, Hestiantoro A, Wijanto P, Li-Yu J, Agdeppa I, Todd JM, Eastell R: The effect of a fortified milk drink on vitamin $D$ status and bone turnover in post-menopausal women from South- East Asia. Bone 2010, 46:759-767.

28. Chie WC, Yang RS, Liu JP, Tsai KS: High incidence rate of hip fracture in Taiwan: estimated from a nationwide health insurance database. Osteoporos Int 2004, 15:998-1002.

29. Miura S, Nakamori M, Yagi M, Saavedra OL, Ikemoto S, Yamamoto S: Daily calcium intake and physical activity status in urban women living on low incomes in Davao, Philippines: a primary study for osteoporosis prevention. J Med Invest 2009, 56:130-135.

30. Miura S, Saavedra OL, Yamamoto S: Osteoporosis in urban postmenopausal women of the Philippines: prevalence and risk factors. Arch Osteoporos 2008, 3:17-24

31. Pongchaiyakul C, Nguyen ND, Eisman JA, Nguyen TV: Clinical risk indices, prediction of osteoporosis, and prevention of fractures: diagnostic consequences and costs. Osteoporos Int 2005, 16:144-1450.

32. Limpaphayom KK, Taechakraichana N, Jaisamrarn U, Bunyavejchevin S, Chaikittisilpa S, Poshyachinda M,Taechamahachai C, Havanond P, Onthuam $Y$, Lumbiganon P, Kamolratanakul P: Prevalence of osteopenia and osteoporosis in Thai women. Menopause 2001, 8(1):65-69.

33. Pongchaiyakul C, Panichkul S, Songpatanasilp T, Nguyen TV: A nomogram for predicting osteoporosis risk based on age, weight and quantitative ultrasound measurement. Osteoporos Int 2007, 18:525-531.

34. Cooper C, Cole ZA, Holroyd CR, Earl SC, Harvey NC, Dennison EM, Melton LJ, Cummings SR, Kanis JA: Secular trends in the incidence of hip and other osteoporotic fractures. Osteoporos Int 2011, 22:1277-1288.

35. Thompson PW, Taylor J, Oliver R, Fisher A: Quantitative ultrasound (QUS) of the heel predicts wrist and osteoporosis-related fractures in women age 45-75 years. J Clin Chem 2006, 1(3):219-225.

36. Bauer DC, Gluer CC, Cauley JA, Vogt TM, Ensrud KE, Genant HK, Black DM: Broadband ultrasound attenuation predicts fractures strongly and independently of densitometry in older women: a prospective study. Study of osteoporotic fractures research group. Arch Intern Med 1997, 157:629-634.

37. Dobnig H, Piswanger-Sölkner JC, Obermayer-Pietsch B, Tiran A, Strele A, Maier E, Maritschnegg P, Riedmuller G, Brueck C, Fahrleitner-Pammer A: Hip and nonvertebral fracture prediction in nursing home patients: role of bone ultrasound and bone marker measurements. J Clin Endocrinol Metabol 2007, 92(5):1678-1686.

38. Hartl F, Tyndall A, Kraenzlin M, Bachmeier C, Gückel C, Senn U, Hans D, Theiler R: Discriminatory ability of quantitative ultrasound parameters and bone mineral density in a population-based sample of postmenopausal women with vertebral fractures: results of the Basel osteoporosis study. J Bone Min Res 2002, 17(2):321-330.

39. Bouxsein ML, Coan BS, Lee SC: Prediction of the strength of the elderly proximal femur by bone mineral density and quantitative ultrasound measurements of the heel and tibia. Bone 1999, 25(1):49-54.

40. Green TJ, Skeaff CM, Rockell JEP, Venn BJ, Lambert A, Todd J, Khor GL, Loh SP, Muslimatun S, Agustina R, Whiting SJ: Vitamin D status and its association with parathyroid hormone concentrations in women of child-bearing age living in Jakarta and Kuala Lumpur. Eur J Clin Nutr 2008, 62:373-378.
41. Chee WSS, Suriah AR, Chan SP, Zaitun Y, Chan YM: The effect of milk supplementation on bone mineral density in postmenopausal Chinese women in Malaysia. Osteoporos Int 2003, 14:828-834.

42. Rahman SA, Chee WSS, Yassin Z, Chan SP: Vitamin D status among postmenopausal Malaysian women. Asia Pacific J Clin Nutr 2004, 13(3):1-7.

43. Oemardi M, Horowitz M, Wishart JM, Judith M, Morris HA, Need AG, O'Loughlin PD, Nordin BEC: The effect of menopause on bone mineral density and bone-related biochemical variables in Indonesian women. Clin Endocrinol 2007, 67:93-100.

44. Reid IR, Ames RW, Evans MC, Gamble GD, Sharpe SJ: Long-term effects of calcium supplementation on bone loss and fractures in postmenopausal women: a randomised controlled trial. Am J Med 1995, 98:331-335.

45. Prince R, Devine A, Dick I, Criddle A, Kerr D, Kent N, Randell A, Price R: The effects of calcium supplementation (milk powder or tablets) and exercise on bone density in postmenopausal women. J Bone Miner Res 1995, 10:1068-1075.

46. Lau EMC, Cooper C: The epidemiology of osteoporosis: the oriental perspective in a world context. Clin Orthop 1996, 323:65-74.

doi:10.1186/1471-2474-14-81

Cite this article as: Kruger et al:: Bone health comparison in seven Asian countries using calcaneal ultrasound. BMC Musculoskeletal Disorders 2013 $14: 81$.

\section{Submit your next manuscript to BioMed Central and take full advantage of:}

- Convenient online submission

- Thorough peer review

- No space constraints or color figure charges

- Immediate publication on acceptance

- Inclusion in PubMed, CAS, Scopus and Google Scholar

- Research which is freely available for redistribution 